\title{
Interactive comment on "Western Mediterranean hydro-climatic consequences of Holocene iceberg advances (Bond events)" by Christoph Zielhofer et al.
}

Christoph Zielhofer et al.

zielhofer@uni-leipzig.de

Received and published: 23 January 2019

Dear Editor, Anonymous Referee \#2 gave as important suggestions about our proxy data set. We will consider his comments in the revised version of our manuscript.

The following paragraphs provide replies to the referee\#2's comments:

Ref\#2: "Introduction and methodology: This study leads off with a thoughtful introduction reviewing and analyzing the North Atlantic (NA) rafted debris record (Bond events) and makes a strong case for Mediterranean studies showing probable linkages of hydroclimate and the Bond event record. Studies identified and compared in this work 
are well summarized, represent a substantial range of Mediterranean sites, and their records compared to highlight regional variability of humidity and dryness, and initially, the authors emphasize caution in attributing these patterns (in response to Atlantic cooling events) to 'forcing mechanisms, or chronological correlations"'.

We thank the ref\#2 for the general positive comment.

Interactive

Ref\#2: "The introduction is bolstered by three well designed figures that present a broad to fine scale descriptions of the study area and place in context the North Atlantic Basin, regional climate patterns, and the coring site depicting the local landscape and vegetation."

We thank the ref\#2 for the general positive comment.

Ref\#2: "The methodology was one of the strengths of this study, with the with addition of 82 new samples to a previously published 180 ostracod record for Lake Sidi Ali in the Middle Atlas range of Morocco. The new samples bring a total number of data points to 182 for $19.63 \mathrm{~m}$ record spanning the Early to Late Holocene (12K cal ybp), and almost doubling the $14 \mathrm{C}$ chronological sample resolution of the previous record from " 130 years to 71.4 years". This robust record is reinforced by $210 \mathrm{~Pb}$ and $137 \mathrm{Cs}$ dating in the historic. The 180 data were further compared with pollen (Cedrus sp.), micro-charcoal, solar activity, solar insolation, as well as a running 25-point correlation between the Bond event IRD record and the Sidi Ali 180 record. Clear figures, stacked with a color overprint of Early to Late Holocene hydroclimate changes and Bond event intervals, strongly reinforce the authors thinking."

We thank the ref\#2 for the general positive comment. Further, we considered comments of the ref\#1 and integrated results of low-pass filtering in the figures. Additionally, we want to restructure the manuscript according to the issues of the ref\#1 (cf. Zielhofer et al. 2018)

Ref\#2: "Hydroclimate: The authors characterize the overall pattern of the Sidi Ali

Printer-friendly version

Discussion paper 
Record in the Early Holocene with Atlantic cooling coupled with dry winters with higher summer temperatures producing drought stress limiting Cedrus. In addition, the early summer warm climate co-occurs with warm Atlantic winter rains, except during Bond events. The record is dramatically reversed, in this reviewer's opinion, for the Late Holocene beginning about $5 \mathrm{~K}$ cal ybp where Atlantic cooling produces wet winters, in a hydroclimate of decreasing rainfall. Both Early and Late Holocene interpretations are supported from additional studies with TOC, diatom, and charcoal; and solar forcing, solar insolation, and chironomid data, respectively. This two-phase change in the Early and Late Holocene 180 record could be described as a marked low frequency, high amplitude signal that sharply decreases in amplitude after $5 \mathrm{~K}$ cal ybp and the into the Mid-Late Holocene, and arguably begins to increase in amplitude and frequency from $\sim 2 \mathrm{~K}$ cal ybp into to the modern."

We thank the ref\#2 for the general positive comment.

Ref\#2: "In addressing the 180 record, this reviewer suggests more description and/or insights from the authors would be helpful to interpret and the patterns of the signal with regards to amplitude and frequency, which this reader found dramatic. Possibly presenting these data with some type of signal-to-noise ratio analyses could be helpful."

Many thanks for this comment. Especially we will emphasise in the discussion chapter the change in amplitude of the 180 signal at $\sim 5 \mathrm{ka}$.

Ref\#2: "Additionally, this same approach could be beneficial comparing and evaluating both the pollen and charcoal data. Clearly, there is a wide range of pollen responses between the 10.2 and 7.2 Bond events, using the Early Holocene as an example. And while both responses are positive, they are clearly different in their absolute values, and appear dissimilar. I would find some characterization and analysis of this variability helpful. A similar argument can be made for the Late Holocene segment in the record, again, especially for the charcoal and pollen records. The Late Holocene charcoal signal depicts an increase in peak values of charcoal, and a variable higher frequency 
pattern of peaks. Some method for identifying fire events, either a threshold of signal to noise ratio, or a confidence interval set from smoothed baseline could potentially sharpen the fire event interpretation."

Many thanks. Actually, we do not plan to follow this suggestion in the overall revision of the manuscript because we restructured the manuscript following the issues of ref\#1 and put the charcoal record out of the millennial-scale interpretation. Further, in the revised version the Cedrus pollen record is discussed as a probable proxy for summer temperature. We added a 1000 yr low-pass filter (Zielhofer et al. 2018) for a better illustration of potential coincidences between decreased subtropical summer heat (deMenocal et al. 2000) and Cedrus increases.

Ref\#2: "Finally, trends in the pollen data, such as the slower rise of Cedrus before the Early/Late Holocene shift in $\delta 180$ record, the change in the frequency of the pollen signal, and frequent occurrence of charcoal peaks beginning about $5 \mathrm{~K}$ cal ybp also suggest there may be additional ecological factors influencing the Cedrus pollen response. Appreciated was the acknowledgment, that settlement history may have had an additional influence in the charcoal record, as is the case with many Holocene paleo-fire reconstructions."

Many thanks. Yes, we add additional thoughts about the ecological factors influencing Cedrus response. Here, the bi-millennial frequency of the Cedrus record might be strong during the Early Holocene due to the generally higher impact of summer solar radiation at that time.

Ref\#2: "4.2 Bond event: An additional strength of this study was the scholarship involved in the introduction and summary of a wide range of regional studies placing the results of the authors in context with the broader Mediterranean. Especially helpful, was the discussion of hydroclimate variability specific to other environmental reconstructions of the 4.2 period across the Mediterranean. The findings of this study showing a cool wet event at the 4.2 Bond event, was nicely contrasted with a number

\section{CPD}

Interactive comment
Printer-friendly version

Discussion paper 
regional studies mostly indicating the 4.2 as a period of dryness. Further, the thoroughness of the authors placing this study in the context of such a wide spectrum of studies throughout the entire paper, potentially could be improved by a table or matrix figure summarizing this study's results and the many citations included within, bringing readers less familiar with Holocene paleo-environments of the Mediterranean region, into the sphere of thinking of the authors."

We thank the ref\#2 for the general positive comment and the helpful suggestion. Right, in the final version of the manuscript we will integrate a matrix figure summarizing major study's conclusions (Fig. 1).

Ref\#2: "Conclusions: This is a well written paper, and should be published with minor revisions. The amplification of the resolution of a previously published record, and subsequent interpretation of that record, is an important and detailed contribution to the understanding of paleo-hydroclimate dynamics of Morocco. In addition, the paper makes a significant case for further investigations of Holocene paleo-hydroclimate scenarios in a broader Mediterranean context, with the comparison of this record to numerous efforts, emphasizing "coherence with Bond events across the entire Holocene" for some areas, yet in contrast, other sites demonstrating a variable step change from a wetter Early Holocene to a Late-Holocene of aridity at $5 \mathrm{~K}$ cal ybp."

We thank the ref\#2 for the general positive comment.

Ref\#2: "Post-script comments on the author response to Anonymous Reviewer 1: Figure, table, and comments submitted in both responses to Reviewer 1, greatly strengthened this submission. Especially helpful were 2 sigma age model panel, in addressing uncertainties, and the 500-year low pass filter on the pollen record and 180 reconstruction clarifying the Cedrus response."

Printer-friendly version

We thank the ref\#2 for the general positive comment.

Kind regards Christoph Zielhofer and all co-authors 


\section{References}

deMenocal, P.B., Ortiz, J., Guilderson, T. \& Sarnthein, M. 2000b. Coherent Highand Low-Latitude Climate Variability During the Holocene Warm Period. Science 288, 2198-2202.

Zielhofer, C., Köhler, A., Mischke, S., Benkaddour, A., Mikdad, A., Fletcher, W.J., 2018. Interactive comment on "Western Mediterranean hydro-climatic consequences of Holocene iceberg advances (Bond events)" Clim. Past Discuss., https://doi.org/10.5194/cp-2018-97-RC2, 2018

Interactive comment on Clim. Past Discuss., https://doi.org/10.5194/cp-2018-97, 2018. 


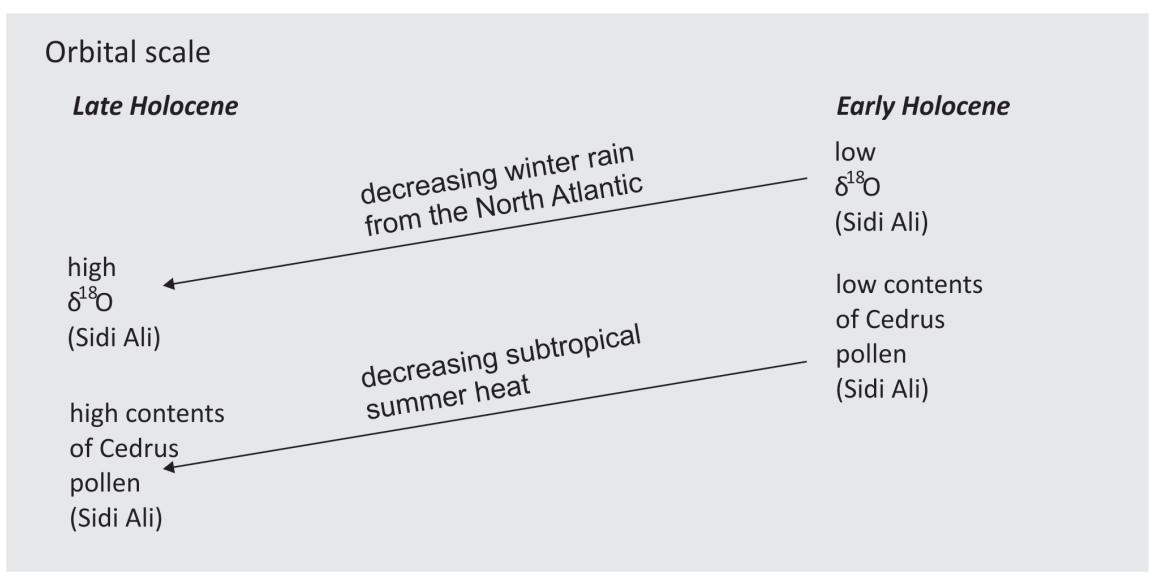

CPD

Centennial- to millennial scale

\begin{tabular}{|c|c|c|c|}
\hline Late Holocene & & & Early Holocene \\
\hline $\begin{array}{l}\text { Winter season } \\
\text { at Sidi Ali: } \quad \rightarrow\end{array}$ & $\begin{array}{l}\text { Cool North Atlantic } \\
\text { Bond events }(4.2,2.7 \text {, } \\
1.2 \text { and } 0.5 \mathrm{ka}) \\
\text { correspond with } \\
\text { W Mediterranean } \\
\text { winter rain maxima }\end{array}$ & $\begin{array}{l}\text { Winter season } \\
\text { at Sidi Ali: } \rightarrow\end{array}$ & $\begin{array}{l}\text { Cool North Atlantic } \\
\text { Bond events ( } 11.4 \text {, } \\
10.2,9.3,8.2 \text { and } \\
6.0 \mathrm{ka}) \text { correspond } \\
\text { with W Mediterranean } \\
\text { winter rain minima }\end{array}$ \\
\hline $\begin{array}{l}\text { Summer season } \\
\text { at Sidi Ali } \longrightarrow\end{array}$ & $\begin{array}{l}\text { Cedrus peaks at } 4.6 \text {, } \\
3.2,1.8 \text { and } 0.5 \mathrm{ka} \\
\text { indicate major phases } \\
\text { of cool subtropical } \\
\text { summers }\end{array}$ & $\begin{array}{l}\text { Summer season } \\
\text { at Sidi Ali } \longrightarrow\end{array}$ & $\begin{array}{l}\text { Cedrus peaks at } \\
10.2,8.2 \text { and } 6.0 \mathrm{ka} \\
\text { indicate major phases } \\
\text { of cool subtropical } \\
\text { summers }\end{array}$ \\
\hline
\end{tabular}

\section{Interactive \\ comment}

Fig. 1. Lake Sidi Ali Holocene core: illustration of major conclusions 